\title{
HETEROSIS AND THE INHERITANCE OF YIELD IN THE TOMATO
}

\author{
WATKIN WILLIAMS and NEIL GILBERT \\ John Innes Horticultural Institution, \\ Bayfordbury, Hertford, Herts
}

Received I5.v.59

\section{INTRODUCTION}

THE diallel cross has achieved considerable popularity in recent years. Our excuse for reporting another one is that ours is much bigger than the others. It provides a worthwhile number of degrees of freedom for comparisons between parents, and so permits an attempt at formulating rules for the breeding of self-fertilising plants such as the tomato. General rules of plant breeding procedure are still conspicuously lacking, and genetical theory contributes less than is generally admitted to crop improvement except in the simpler kinds of character transference. The complexity of the inheritance of quantitative characters defies even the most sophisticated theoretical attempts at a measure of rationalisation that would be helpful in the prediction and manipulation of progenies. It has been decided therefore in describing the present material that consideration other than of the phenotypic behaviour of the parents and crosses would be of little use.

One of the chief interests in general breeding work in recent years has been in the utilisation of heterosis. The most striking success in this field has been in out-breeding species, particularly maize in which separation of the sexes leads to economical production of hybrid seed. With inbreeding crops such as the tomato, the practical importance of heterosis is less clear (Williams, 1959a), and it is doubtful whether hybridity per se has any advantage for increasing character expression when compared with pure lines. The replication afforded by the present diallel cross can assist in determining the relative importance of heterosis in self-fertilising crops.

Gilbert (1958) following an analysis of all available evidence from diallel crosses in several different species concluded that the value of the diallel cross in plant breeding should not be exaggerated, and that the information gained from it is very little more than that obtained from the parents themselves. In this work it is proposed to expose some of the details underlying this generalisation and by so doing to draw attention to certain aspects of behaviour of the parent varieties which are reproducible over a wide range of crosses.

\section{MATERIALS AND METHODS}

The parents were Vetomold, Kondine Red, Stonor's Exhibition, Ailsa Craig, Harbinger, Potential, Potentate, Vagabond, Leafmould Resister I, Plumpton King, 
Radio, Moneymaker, Comet, Crackerjack, Baby Lea, Downes' Seedling, E.S.r and Delicious. Most of these varieties have been under observation here for many years, and as far as can be determined the samples were true to name. The $F_{1}$ 's and parents were grown in a glasshouse in 1957, using a lattice square design with six replicates and one plant per plot. In $195^{8}$ the $F_{1}$ 's and parents were grown out of doors in a lattice square with two replicates and three plants per plot.

The yields (in ounces) and fruit numbers are given on a per-plant basis, so that the $F_{1}$ figures (and the parents grown with them) for each year are the means of six plants each. The average fruit weights (ounces) were calculated from the total yields of three plants each, so that the figures quoted here are the means of two average fruit weights per cross per year. All figures presented refer to records taken during the first three weeks of fruiting.

\section{THE PERFORMANCE OF THE PARENTS}

Apart from the few varieties released following systematic breeding by Stonor (unpublished), Bewley (1930-53) and Crane (I951), the majority of tomato varieties at present in cultivation in England are of uncertain origin. Of the 18 varieties used in the present diallel cross only the origins of Vagabond, Vetomold, L.M.R. No. I and E.S.I are known with certainty. Exhibition and Moneymaker are known to have been derived from the "green-top " $(U)$ form by introducing the gene $u$ for uniform fruit colour from Devon Surprise, but no information is available on the other parents used in the crosses. The range of genetic variation in English tomato varieties cannot therefore be assessed and one is probably dealing in many cases with very similar types and perhaps even with synonyms. The work described here can assist in the resolution of genetic differences between the varieties used because their contributions to i 7 different hybrids in two different environments have been determined. This diallel cross provides extensive data on the transmission of characters by the parents, and enables one to assess the extent of genetic diversity in agronomically similar varieties.

Some of the $\mathrm{I} 8$ varieties fall into two fairly well defined groups.

Groups A and B differ in average fruit weight and in fruit number. Varieties in group A produce a large number of small fruit, giving a large yield, while those in group B have a smaller number of large fruit and a poor yield. These groups are characterised not merely by these numerical observations but also by the strikingly similar appearance of varieties in each group.

It will be noted that none of the 18 varieties combined maximal fruit number with maximal fruit weight. At their upper limits, these two components of yield are almost certainly mutually exclusive. The correlation between average fruit weight and fruit number in these 18 parents was -0.66 .

The most important component of yield, given the range of average fruit weights in the present series of varieties, is fruit number. The correlation between fruit number and early yield is 0.80 . Since varieties with respectively smaller or larger fruits than the smallest 
or largest represented here have little use commercially, it can be concluded that in the cultivated tomato maximal yield can only be achieved in forms which have the capacity to ripen large numbers of fruit.

Earliness of ripening in the tomato is governed by rate of development during two stages of growth of the seedling (Williams, 1959b).

TABLE I

The levels of yield and yield components in 18 parent varieties.

First 3 weeks' yield $1957+1958$

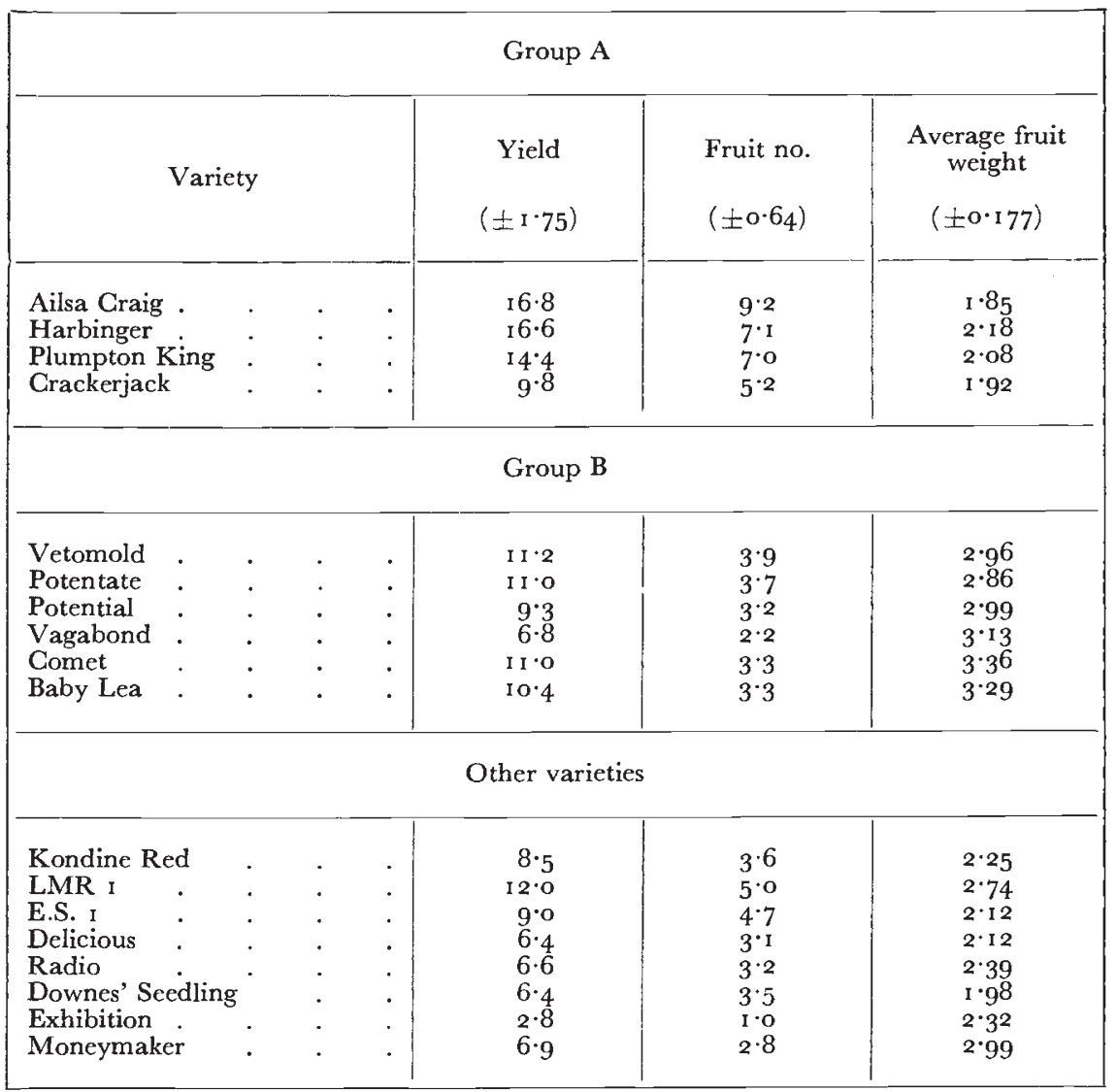

In different varieties the rate of development to first flower relative to that from first flower to first ripe fruit frequently differs. In the present series of parents the time to flowering under glass in varieties of group A was on average greater than in those of group B. Since group A varieties produced a significantly greater number of early fruit than those in group B it is clear that they develop at a far more rapid rate than the latter during the period from flowering to fruit ripening. Hybrid combinations between varieties which develop 
rapidly during different periods gave the best early yield in the $F_{1}$ families. years.

Table 2 compares the behaviour of parent varieties in the two

In this and in some later tables the best and poorest parents have been selected on their performance in 1957. Table I shows that different sets of five must be selected for different characters. It must be remembered that a "poor" variety might be selected, not because it is an inferior performer in that environment, but because the six plants representing it happened to be rather poor specimens. Such a variety could be expected to recover even if grown again in identical conditions. The act of selection may bias our figures. The fact remains that the parents behave differently ( $c f$. Appendix) and that this

TABLE 2

Average performance of parents in 1957 and $195^{8}$

\begin{tabular}{|c|c|c|c|}
\hline Character & $\begin{array}{l}\text { General } \\
\text { average }\end{array}$ & $\begin{array}{c}\text { Average } \\
\text { top 5, } 1957\end{array}$ & $\begin{array}{c}\text { Average } \\
\text { bottom 5, I957 }\end{array}$ \\
\hline 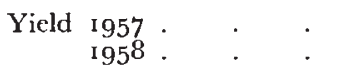 & $\begin{array}{r}8 \cdot 8 \\
10 \cdot 8\end{array}$ & $\begin{array}{l}13 \cdot 6 \\
11 \cdot 9\end{array}$ & $\begin{array}{l}3 \cdot 9 \\
8 \cdot 5\end{array}$ \\
\hline $\begin{array}{rr}\text { Fruit number } & 1957 \\
& 195^{8}\end{array}$ & $\begin{array}{l}3 \cdot 2 \\
5 \cdot 1\end{array}$ & $\begin{array}{l}5 \cdot 7 \\
7 \cdot 6\end{array}$ & $\begin{array}{l}I \cdot 4 \\
4 \cdot I\end{array}$ \\
\hline $\begin{aligned} \text { Average fruit weight } & \text { } 957 \\
& \text { I } 95^{8}\end{aligned}$ & $\begin{array}{l}2 \cdot 86 \\
2 \cdot 20\end{array}$ & $\begin{array}{l}3 \cdot 63 \\
2 \cdot 6 \mathrm{I}\end{array}$ & $\begin{array}{l}2 \cdot 13 \\
I \cdot 91\end{array}$ \\
\hline
\end{tabular}

has to be considered in discussion of the $F_{1}$ results. The five best varieties under glass showed a drop in early yield when grown outdoors, while the poorest increased by 120 per cent. Similarly with regard to fruit number, the best varieties improved only 33 per cent. when field grown while the varieties with low fruit number showed an increase of nearly 200 per cent. The most important difference, however, was in average fruit weight. The difference in general average fruit weight between the two years is apparently due to a reduction mainly in varieties with large fruit. It is worth noting that between 1957 and 1958, fruit number increased and fruit size decreased in these varieties, and that the fluctuations compensated differently in the different varieties, thus producing relative differences in yield. As will be shown later, this unequal behaviour of the varieties can affect any conclusions regarding heterosis in the $F_{1}$ families.

\section{THE PERFORMANCE OF $F_{1}$ HYBRIDS}

It has been shown (Gilbert, I958) that the average performance of hybrids is closely related to the behaviour of the parents. The best parent for a particular character gave on average the best set of $F_{1}$ families in the diallel cross. Interactions between parents (i.e. specific 
combining abilities) were negligible and the interactions that did occur varied widely from year to year (see Appendix). Thus it appears that the principle of knowing the best and breeding from them cannot be improved in any radical way. However, in order to allow this generalisation to be used in the most purposeful way in a breeding programme it is necessary to examine the data in somewhat greater detail.

Williams (r959c) suggested that heterosis for yield was the consequence of multiplicative relationships on the phenotypic or somatic level (Mather, 1949) between the component characters of the yield complex. Yield in the tomato is primarily made up of fruit number and average fruit weight, and heterosis for total early yield (weight), can occur in hybrids in which the component characters merely show dominant or intermediate levels of expression. For this to occur the parents must differ as regards the level of expression of each of the components and neither must have a monopoly of high (or low) expression in both the unit characters. Thus yield heterosis becomes simply an expression of an inequality known to mathematicians as Tchebychev's. The following is a simple case:

\begin{tabular}{|c|c|c|c|c|}
\hline & & $\begin{array}{l}\text { Ist component } \\
\text { of yield }\end{array}$ & $\begin{array}{l}\text { 2nd component } \\
\text { of yield }\end{array}$ & Yield \\
\hline Parent A & . & I & 3 & 3 \\
\hline Parent B & . & 3 & I & 3 \\
\hline$F_{1}(A \times B)$ & . & 2 & 2 & 4 \\
\hline
\end{tabular}

These preliminary conclusions can now be supported by the far more extensive data from the $\mathrm{I} 8 \times \mathrm{r} 8$ diallel cross.

The "top-parent" in each cross is the one that gives the best performance. Where the $F_{1}$ mean in table 3 is no greater than the " top-parent" mean, the $\mathrm{F}_{1}$ families on average do not exhibit heterosis. Apart from average fruit weight in 1958 , which will be discussed in greater detail later, the hybrids show no heterosis for the components of yield. Yield itself, on the other hand, is clearly heterotic in the two environments.

In this connection reference may be made to the ro $\times$ ro diallel cross between tomato lines reported by Powers (1945). Although the enormous phenotypic differences between the parents used make the averages rather unsatisfactory, they can be used for present purposes. A summary of Powers' data similar to that given in table 3 is given in table 4 .

The standard errors of different varieties were heterogeneous and this has been allowed for in calculating the S.E. of the average "topparent ". Examination of individual crosses reveals heterosis for yield. Fruit weight shows no heterosis and fruit number is heterotic only in the three crosses between the three lowest parents. 
Thus in all these data, heterosis for yield is a property of the phenotype requiring no special genetical explanation. It must be understood

TABLE 3

Mean values of all $F_{1}$ families

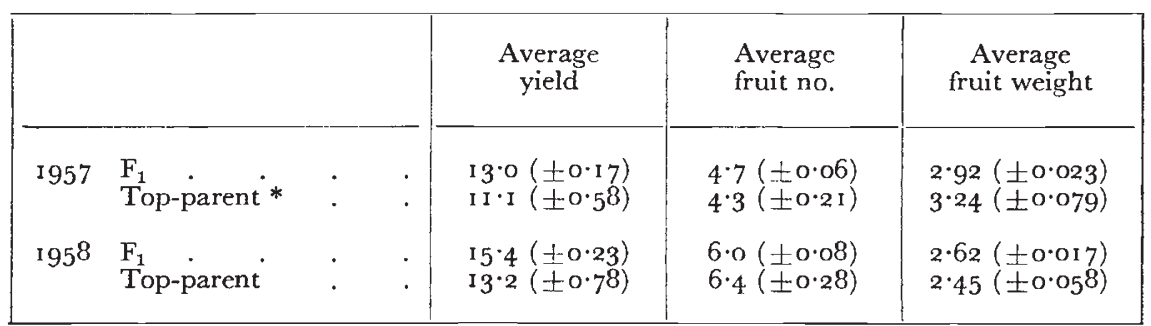

* The error variance of the mean of the "top-parent" in a $k \times k$ diallel cross is $\frac{2(2 k-1)}{3 k(k-1)} \sigma^{2}$, where $\sigma^{2}$ is the error variance of one parent.

that the complexity of the component characters is also very great and that consequently we are no nearer to consideration of basic cell

TABLE 4

Mean values of all $F_{1}$ families from Powers (1945)

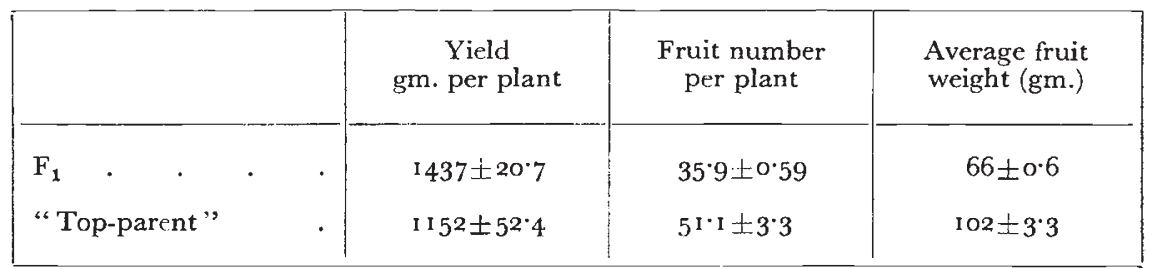

processes. Fortunately this need not concern us here since our primary interest is in the phenotype.

\section{THE RELATIONSHIP BETWEEN PARENTS AND $F_{1}$ HYBRIDS}

In the absence of sizable interaction, the main effects derived from arrays of 17 hybrids involving a common parent in the diallel are a measure of which parents yield the best hybrids.

Table 5 shows that the main effects correspond to the parental order with respect to all the characters although differences do exist which are statistically-and, we must presume, genetically-significant (see Appendix). In fact, as with the parents, the best hybrid series are those which produce high fruit numbers at the expense of fruit size. An examination of the individual hybrids in the arrays shows that the majority of the high yielding hybrids are to be found in crosses involving Ailsa Craig and Harbinger. In relation to general economy in a breeding programme, extensive "top-crosses" with 
either or perhaps both of these parents would have resulted in the identification of the greater proportion of the most promising crosses.

The equality of these two varieties with respect to yield characters, and the high degree of correspondence between their $F_{1}$ hybrids raise doubts as to whether they are in fact distinct varieties, and highlights

TABLE 5

Correlations between main effects and parental values

(Each correlation has 16 d.f.)

\begin{tabular}{|c|c|c|c|}
\hline & Yield & Fruit no. & Fruit weight \\
\hline 1957 & 0.62 & 0.78 & 0.82 \\
$195^{8}$ & 0.58 & 0.73 & 0.80 \\
\hline
\end{tabular}

the question of synonyms mentioned earlier. Their breeding behaviour suggests that, at least for all practical purposes, they can be considered to be identical.

The performance of the hybrids is given in table 6 .

TABLE 6

Mean value of hybrids in 1957 and $195^{8}$

\begin{tabular}{|c|c|c|c|}
\hline Character and year & $\begin{array}{c}\text { General average } \\
\text { (I53 hybrids) }\end{array}$ & $\begin{array}{l}\text { Average top five } \\
\text { arrays (1957) * }\end{array}$ & $\begin{array}{l}\text { Average bottom } \\
\text { five arrays (1 } 957)^{*}\end{array}$ \\
\hline $\begin{array}{rr}\text { Yield (oz.) } & 1957 . \\
& 195^{8} \\
\end{array}$ & $\begin{array}{l}13 \cdot 0 \\
15 \cdot 4\end{array}$ & $\begin{array}{l}15 \cdot 7 \\
17 \cdot 6\end{array}$ & $\begin{array}{l}\text { 10.6 } \\
\text { г } 3.9\end{array}$ \\
\hline $\begin{array}{ll}\text { Fruit number } & \text { 1957 } \\
& 1958\end{array}$ & $\begin{array}{l}4 \cdot 7 \\
6 \cdot 0\end{array}$ & $\begin{array}{l}6 \cdot I \\
7 \cdot 0\end{array}$ & $\begin{array}{l}3 \cdot 7 \\
5 \cdot 4\end{array}$ \\
\hline $\begin{array}{ll}\text { Av. fruit weight (oz.) } & 1957 \\
& 195^{8}\end{array}$ & $\begin{array}{l}2 \cdot 92 \\
2 \cdot 62\end{array}$ & $\begin{array}{l}3 \cdot 26 \\
2 \cdot 76\end{array}$ & $\begin{array}{l}2 \cdot 54 \\
2 \cdot 38\end{array}$ \\
\hline
\end{tabular}

* The top and bottom five arrays were selected on the 1957 data. The arrays taken need not be the same for each of the three characters. Those hybrids which occur in two of the five arrays are counted twice.

The tendency towards equalisation in yield in 1958 which occurred in the parents does not occur in the $\mathrm{F}_{1}$ hybrids ( $c f$. Appendix). The hybrids gave a more consistent performance under the highly contrasting conditions of the two environments both as regards yield and the component characters of yield.

\section{HETEROSIS FOR YIELD AND COMPONENT CHARACTERS OF YIELD IN INDIVIDUAL CROSSES}

The prevalence of heterosis in any crop species has practical as well as theoretical implication since success in the production of superiorhybrids will depend greatly on the frequency of heterotic combinations. An assessment of the occurrence of heterosis as a general 
phenomenon as opposed to isolated cases is therefore considered to be of the utmost importance. It is impracticable in an extensive diallel cross such as the present one to undertake the extensive testing necessary to establish beyond doubt the presence of heterosis in each cross that shows excess over the top-parent. We consider therefore that the examination of groups of means within a large diallel cross is the only practical method of detecting heterosis as a general phenomenon.

It is frequently assumed in discussions on the practical utilisation of heterosis, that any $\mathrm{F}_{1}$ hybrid which is recorded as being significantly

TABLE 7

Two $5 \times 5$ diallel crosses showing deviation of each hybrid from its top-parent (1957 yield)

\begin{tabular}{|c|c|c|c|c|}
\hline & $\begin{array}{l}\text { Plumpton } \\
\text { King }\end{array}$ & Harbinger & Potentate & Vetomold \\
\hline & \multicolumn{4}{|c|}{$( \pm 2 \cdot 94)$} \\
\hline $\begin{array}{l}\text { Harbinger } \\
\text { Potentate } \\
\text { Vetomold } \\
\text { Baby Lea }\end{array}$ & $\begin{aligned} & 0 \\
&-7 \cdot 7 \\
&-1 \cdot 0 \\
&+o \cdot 8\end{aligned}$ & $\begin{array}{r}+5 \cdot 8 \\
-4 \cdot 2 \\
+6.0\end{array}$ & $\begin{array}{c}-3 \cdot 2 \\
0\end{array}$ & $+1 \cdot 7$ \\
\hline \multicolumn{5}{|c|}{ (b) Five parents with low yield } \\
\hline & Exhibition & Delicious & $\begin{array}{l}\text { Downes' } \\
\text { Scedling }\end{array}$ & Moneymaker \\
\hline & \multicolumn{4}{|c|}{$( \pm 2 \cdot 94)$} \\
\hline $\begin{array}{l}\text { Delicious } \\
\text { Downes' Secdling } \\
\text { Moneymaker . } \\
\text { Kondine Red . }\end{array}$ & $\begin{array}{r}+6 \cdot 0 \\
+3 \cdot 2 \\
+2 \cdot 5 \\
+13.2\end{array}$ & $\begin{array}{r}+6.3 \\
+-1 \cdot 2 \\
+7.8\end{array}$ & $\begin{array}{l}+6 \cdot 0 \\
+9.8\end{array}$ & $+7 \cdot 8$ \\
\hline
\end{tabular}

greater than the best parent in the given cross is support for the use of $\mathrm{F}_{1}$ hybrids in practice. While heterosis might be recognised in crosses between parents of less than maximal expression, unless it achieves a level greater than in the best parents available, it can have no practical significance. To establish the existence of heterosis for yield in any given cross may be of some theoretical interest, but unless it can be shown that the level achieved is equal to or better than that of the best parent available, the exercise is futile in terms of better tomato varieties.

The mean yield of the $\mathrm{F}_{1}$ families produced by the three best varieties was slightly less than would be expected on the assumption 
of dominance of high yield. In other words the best varieties were in general better than their hybrids. Superiority of the hybrids over the best parent occurred in this material only when the parents used were below maximal levels. Thus it appears that the expression of heterosis in the tomato largely depends on the choice of parents. Table 7 illustrates this point.

If individual hybrids in table $7 a$ are considered, it might be concluded that the combinations Potentate $\times$ Harbinger and Baby Lea $\times$ Harbinger are heterotic but this can only be definitely established

TABLE 8

Two $5 \times 5$ diallel crosses showing deviation of each hybrid from its top-parent (1957 fruit number)

\begin{tabular}{|c|c|c|c|c|}
\hline & $\begin{array}{l}\text { Plumpton } \\
\text { King }\end{array}$ & Harbinger & Ailsa Craig & Crackerjack \\
\hline & \multicolumn{4}{|c|}{$( \pm \mathrm{I} \cdot 08)$} \\
\hline $\begin{array}{l}\text { Harbinger } \\
\text { Ailsa Craig } \\
\text { Crackerjack } \\
\text { E.S.I }\end{array}$ & $\begin{array}{l}+0 \cdot 7 \\
-0 \cdot 5 \\
-2 \cdot 2 \\
-2 \cdot 0\end{array}$ & $\begin{array}{l}+4.5 \\
-0.7 \\
+1 \cdot 0\end{array}$ & $\begin{array}{l}+3 \cdot 0 \\
+2 \cdot 7\end{array}$ & $-1 \cdot 0$ \\
\hline \multicolumn{5}{|c|}{ (b) Five parents with low fruit number } \\
\hline & Exhibition & Moneymaker & $\begin{array}{l}\text { Downes' } \\
\text { Seedling }\end{array}$ & Delicious \\
\hline & \multicolumn{4}{|c|}{$( \pm \mathbf{r} \cdot \circ 8)$} \\
\hline $\begin{array}{l}\text { Moneymaker } \\
\text { Downes' Seedling } \\
\text { Delicious } \\
\text { Comet . }\end{array}$ & $\begin{array}{l}+0.7 \\
+0.7 \\
+1.3 \\
+2.5\end{array}$ & $\begin{array}{r}+2.0 \\
+0.7 \\
+1.2\end{array}$ & $\begin{array}{l}+3.0 \\
+2.7\end{array}$ & +0.7 \\
\hline
\end{tabular}

after further extensive testing. These two deviations are not significantly different from zero, whereas all ten values in $7 b$ are positive and several are "significant".

\section{(i) Fruit number}

The absence of heterosis in yield characters noted in a previous section referred to the overall behaviour of all the crosses. However, examination of the individual crosses shows that heterosis for fruit number is not absent in all the hybrids, and that (as in Powers' data) parents having low fruit numbers, in general give rise to hybrids in which number of fruit is heterotic (table 8). Varieties with high 
fruit number are on average superior to their hybrids. Because of this, the average fruit numbers for top-parents and hybrids in the whole diallel are still equal (table 3). It appears that heterosis is completely absent in unitary yield characters only when one is dealing with genotypes capable of maximal expression in the character concerned. It must be pointed out however that table $8 a$ involves all four members of group A, and as has already been noted, some of the varieties within this group are genetically very similar. Again, the conclusion that the positive deviations in table $8 a$ are merely due to chance may be overpessimistic, but is unavoidable without further data.

\section{(ii) Average fruit weight}

Under glasshouse conditions in I957, the fruit weight of the $F_{1}$ hybrids agreed with the mid-parent value, while in the field trial the hybrids were on average heterotic for this character. It will be seen from tables 2 and 6 that the five large fruited parents were relatively much less stable as regards fruit weight than the large fruited hybrids under the two environments. Of the large fruited parents only Comet and Baby Lea gave similar fruit weights in the two tests, and these two varieties showed no average heterosis in their respective sets of hybrids in the $195^{8}$ test. The remaining large fruited varieties produced significantly lighter fruit and were inferior to their $F_{1}$ hybrids when grown in the field. The sudden appearance of heterosis for fruit weight in one season can therefore be explained by the behaviour of the parents. It is clear that the hybrids provide a better buffer against environmental influences than the pure lines, and that their relative stability is the property of their genotypes. The genetic system operating in both environments is, however, the same and the danger of ascribing speculative properties, such as over-dominance, to the genotype in individual experiments where heterosis is apparent could not be clearer.

\section{(iii) Flowering date}

Since the time taken from germination to flowering is one of the important factors determining earliness, a record is necessary of the observations on flowering date made on the present material. The mean flowering date of the I53 hybrids equalled the mean of the earliest parent. The mean deviation from expectation assuming phenotypic dominance of earliness was -0.32 days $( \pm 0.2 \mathrm{I} 4)$. The mean deviation in $\mathrm{F}_{1}$ series each containing $\mathrm{I} 7$ hybrids from the five earliest parents was $+0 \cdot 69$ days while the comparable figure from the five latest parents was $-0 \cdot 70$ days. The mean flowering date of hybrids derived from early varieties was slightly later than the mean of the earliest parent, while hybrids from late parents were heterotic for earlier flowering. In this character also it appears that such heterosis as exists is a property of hybrids involving mediocre parents. 


\section{DISCUSSION}

The results outlined here show certain simple patterns of behaviour in the breeding performance of cultivated varieties of the tomato. In all the characters studied, with the exception of average fruit weight when the material was grown under glass, the mean of the I 53 hybrids equalled or exceeded the mean of the top-parent. In their distribution about this average, however, they followed the midparent (Appendix). The top-parent for flowering date is here regarded as the earliest parent. The following summary of the average of 153 deviations for each character will serve to emphasise the constancy of behaviour in the hybrids:

\begin{tabular}{|c|c|c|}
\hline \multirow{2}{*}{ Character } & \multicolumn{2}{|c|}{ Average deviation from: } \\
\hline & Top-parent & Mid-parent \\
\hline $\begin{array}{l}\text { Yield } \\
\text { Fruit number } \\
\text { Average fruit weight } \\
\text { Flowering date (days) }\end{array}$ & $\begin{array}{l}+\mathrm{r} \cdot 8( \pm 0 \cdot 60) \\
+0.4( \pm 0.22) \\
-0.32( \pm 0 \cdot 082) \\
-0.32( \pm 0.214)\end{array}$ & $\begin{array}{l}+4 \cdot 2( \pm 0.52) \\
+1 \cdot 4( \pm 0 \cdot 19) \\
+0 \cdot 06( \pm 0.071) \\
-1 \cdot 32( \pm 0.186)\end{array}$ \\
\hline
\end{tabular}

The above figures refer to 1957 and, apart from the behaviour of fruit weight already noted, are similar to the $195^{8}$ records. The means for all crosses show heterosis only with respect to early yield. Since the general mean for fruit weight was intermediate between the mean of the parents, and since the general mean for fruit number showed no better than the top-parent, it seems clear that the greater part of the heterosis for yield observed in this experiment was of a kind resulting from alternation of high and low expression in the yield components in the parents. It appears therefore that it is quite misleading to talk in terms of heterotic yield genes unless one knows precisely whether the component characters show heterosis. The observation made here is that heterotic yield levels may be achieved in hybrids which, with respect to the component units, show no heterosis and that therefore there is no need to postulate a special genetic system to explain heterosis. This also was the view of Hagberg (1952), who concluded that most of the heterosis in Galeopsis material was of a type which he termed " combination heterosis".

One feature of great importance that is consistent throughout these data, is the general absence of heterosis with respect to all characters where parents with a high level of expression are involved. Heterosis in the tomato is expressed most frequently in hybrids between the poorer genotypes. Inbreeding species which do not show losses in vigour on inbreeding can be expected to have achieved as a result of selection, maximal levels of character expression in pure breeding, relatively homozygous lines. This has been confirmed in the tomato 
(Williams, r959a). With reference to total early yield, and omitting consideration of subjective characters such as fruit quality, very few of the hybrids which showed heterosis, surpassed either the best nonheterotic hybrid or therefore the best parent. Thus although heterotic hybrids do occur, any value that the majority of them have in practice will depend on improvements in characters other than total early yield.

The occurrence of heterosis only among the hybrids of parents in the lower part of the range of variation indicates that in the tomato, and possibly in other inbreeders also, a near maximal level of expression in absolute yield has been achieved by selection. This does not presuppose that at some future date, following the introduction of new material, the present maximum cannot be exceeded. Furthermore, from the genetical standpoint, it appears that the best parents possess genotypes which are balanced at a very high level, while the poorer parents complement each other in a manner that leads to heterosis. Indeed, the entire series studied here seems to behave according to a simple scheme based on complementary factors with varying degrees of dominance. It must be emphasised that no precise meaning can be attached to the use of the term "complementary factor" in this connection, since the relative importance of inter-allelic interaction (Mather, I949; Jinks, 1955) as opposed to somatic interaction (see p. 137) in determining heterosis in the material cannot be decided. The present results agree fully with the interpretation of heterosis given by Keeble and Pellew (I9Io). This somewhat surprising conclusion suggests that much of the obscurity that at present surrounds the problem of heterosis arises from the failure to recognise the component characters of complex phenotypic expressions.

\section{SUMMARY}

I. The behaviour of 153 hybrids derived from 18 parent varieties of tomato has been recorded in two different environments. The characters observed included yield, fruit number, fruit weight, and flowering date.

2. It is concluded that the greater part of the average heterosis for yield in the material is due simply to the relative distribution of the levels of the components of yield in the parents of a given cross. Instances are described of yield heterosis in crosses where the components of yield were not heterotic. In naturally inbreeding species, many other characters which exhibit heterosis probably behave in this manner. It is suggested therefore that it is erroneous to speak of heterotic genes for complex characters such as crop yield.

3. Heterosis in this material was largely confined to crosses between parents which were below observed maxima in the range of variation of a particular character. Near maximal levels have been fixed in the pure breeding varieties which fall in the upper ranges of variation, 
and these are not exceeded by heterotic hybrids between poorer parents.

4. The behaviour of the entire range of hybrids is consistent with a controlling genetic system that is based on complementary gene action with an unknown, and possibly variable, degree of dominance.

5. In the Appendix it is shown that statistical interactions between parents fluctuate from generation to generation; that the discrepancy between the yield of a parent and its general combining ability cannot yet be ignored; and that parents transmit variability of performance, as well as average performance, to their offspring.

Acknowledgments.-We wish to thank Dr F. Yates, F.R.s. for the use of the Rothamsted electronic computer, and Dr K. S. Dodds, D.sc. for valuable help with the manuscript.

\section{REFERENCES}

BEwLEy, W. F. 1930-53. Reports on tomato investigations. Ann. Reps. Cheshunt Expt. St.

CRAne, M. B. I95I. Tomatoes: hybrid vigour. Fohn Innes Ann. Rep., pp. I I-1 2. GILBERT, N. E. I958. Diallel cross in plant breeding. Heredity, 12, 477-492.

GRIFFING, BRUCE. 1950. Analysis of quantitative gene action by constant-parent regression and related techniques. Genetics, 35, 303-32 I.

HAGBERG, A. 1952. Heterosis in $\mathrm{F}_{1}$ combinations in Galeopsis. Hereditas, 38, 221245.

haldane, J. B. s. 1957. Karl Pearson. Biometrika, 44, 303-313.

Hull, F. H. 1946. Maize Genetics Co-operation Neres Letter, 20.

JINks, J. L. 1955. Heterosis in diallel crosses. Heredity, 9, 223-238.

KEEBle, F., AND PELlew, C. IgIo. The mode of inheritance of stature and time of flowering in peas $P$. sativum. F. Genet., $1,47-56$.

MATHER, K. 1949. Biometrical Analysis. Methuen \& Co., London.

POWERS, L. I945. Relative yields of inbred lines and $\mathrm{F}_{1}$ hybrids of tomato. Bot. Gaz., 106, 247-268.

WILliams, $w$. 1959a. The isolation of pure lines from $F_{1}$ hybrids of tomato and the problem of heterosis in inbreeding crop species. F. Agric. Sci. 53, 347-353.

wILliams, w. 1959b. Investigations on the tomato : the control of early fruiting. Fohn Innes Ann. Rep., p. I3.

williams, w. 1959c. Heterosis and the genetics of complex characters. Nature, $184,527-530$. 